\title{
Prostate cancer awareness and attitude toward early detection among male soldiers in Ghana: a cross-sectional study
}

\author{
Juliana Gyasi Necku' ${ }^{1}$ Emmanuel Anongeba Anaba ${ }^{2^{*}}$ and Aaron Asibi Abuosi ${ }^{2}$
}

\begin{abstract}
Background: Prostate cancer (PC) is the leading cause of cancer deaths among men in Ghana. This poses a public health threat, especially among the Ghana Armed Force (GAF) where the majority are males. This study aimed to assess male soldiers' awareness, knowledge and attitudes toward early detection of prostate cancer.

Results: It was found that $58.3 \%$ of the soldiers were less aware of PC and $76.0 \%$ had low or neutral knowledge regarding risk factors and symptoms of PC. The soldiers had positive attitudes toward early detection but had low intentions of getting tested. Awareness was significantly associated with education, rank, haven received PC information from a health worker and being knowledgeable of signs of PC.

Conclusion: We recommend that management of the GAF should liaise with the Ministry of Health to sensitize and educate soldiers on prostate cancer, and if possible, organize periodic screening activities for the soldiers to aid in early detection and effective management of the disease. The findings of this study provide valuable information for health interventions in Ghana.
\end{abstract}

Keywords: Prostate, Cancer, Knowledge, Attitudes, Ghana

\section{Background}

The incidence of prostate cancer (PC) is increasing in sub-Saharan Africa. It is among the most commonly diagnosed cancers among men in the subregion. Despite the increasing trend of PC in the subregion, there is paucity of research on the disease. Also, prostate cancer awareness and knowledge about its prevention is low in the subregion [1-3].

Men in Ghana have an average life expectancy of 62.47 years compared to 71.61 years and 51 years in Mauritius and Lesotho, respectively [4]. Thus, men in Ghana are more likely to live up to their sixties. Out of every three men of 40 years and above in Ghana, one is at risk of PC [5]. The incidence of PC in Ghana is increasing $[6,7]$, and $\mathrm{PC}$ is now the second leading cause of cancer deaths among men in the country. However, Ghana has

\footnotetext{
*Correspondence: emmaanaba24@gmail.com

${ }^{2}$ Public Administration and Health Services Management, University

of Ghana Business School, Accra, Ghana

Full list of author information is available at the end of the article
}

no cancer register partly due to poor record keeping on the disease [6, 8]. This makes it difficult to determine the prevalence rate. Furthermore, there is paucity of the literature on awareness and knowledge of $\mathrm{PC}$ and attitude toward PC screening in Ghana [9]. Screening has been identified as an effective tool for early detection of prostate cancer. However, screening for PC is low in Ghana, resulting in late detection, poor management and rise in PC mortality rate.

Majority of GAF soldiers are males and therefore at risk of developing prostate cancer. The role of the Ghana Armed Forces (GAF) in promoting national and international security cannot be underestimated. In this regard, promoting the health and well-being of soldiers is very important and has implications for national development. According to Otoo [10], the study setting records high numbers of PC cases among soldiers every year and most of the recorded cases are usually at its late stage. Joseph [11] also found that African-American soldiers were less willing to get screened for PC. To help improve 
the health and well-being of soldiers in Ghana, stakeholders would need evidence-based information to plan health interventions. However, studies regarding Ghanaian soldiers' awareness, knowledge and attitudes toward early detection of PC remain sparse. This study therefore sought to address this knowledge gap.

\section{Methods}

The Ghana Armed Force is under the Ministry of Defense. The study used Burma Camp-Accra as a case. Burma Camp is a Military camp named after the Burma war. It is within the La Sub-Metropolis which covers Teshie, Lamansaamokpe and La in the Accra Metropolis, Ghana's capital. Most of the Ghana Armed Force units in Accra are found in and around Burma Camp. The force has three major divisions, namely the Ghana Navy, Ghana Army and Ghana Air Force. GAF is dominated by males, accounting for about $98 \%$ of the total force.

Descriptive cross-sectional survey design was adopted. Male soldiers living in Burma Camp were the target population for the study. The camp has about five hundred (500) male soldiers, both active and reserved. Simple random sampling technique was employed to select respondents. Male soldiers who showed interest of participation were asked to draw from a box containing folded pieces of paper with 'Yes' and 'No' inscription. The picking of a 'Yes' or a 'No' was only based on chance; therefore, the researcher did not have any influence in the selection of the respondents. The sample size was determined using OpenEpi Info software (Open Source Epidemiologic Statistics for Public Health) version 3.01, developed by Centre for Disease Control and Prevention. The software calculates sample size using the design effect, population size, estimated proportion and desired absolute precision. The sample size for this study was determined using a design effect of 1 and an estimated proportion of $50 \%$ which is the default percentage when the researcher is not sure of the exact percentage of the population that will respond to the outcome variable, and desired absolute precision of $5 \%$. The calculated sample size was 218 male soldiers, but the data collector was able to administered 140 questionnaires due to reluctance of soldiers to participate. This is equivalent to $64 \%$ response rate.

Formula for calculating sample size

$$
n=\operatorname{deff} \times \frac{N p q}{\frac{d^{2}}{1.96^{2}}(N-1)+p q}
$$

$n=$ sample size, deff $=$ design effect, $N=$ population size, $p=$ estimated proportion, $q=1-p, d=$ desired absolute precision/absolute level of precision.
A structured questionnaire was administered to 140 male soldiers. The questionnaire was designed in English language and categorized into three main sections. Section one covered bio-data (i.e., age, education etc.) of respondents. Section two contained items assessing soldiers' awareness (i.e., Have you heard of prostate cancer before?) and knowledge about PC (i.e., prostate cancer is sexually transmitted) on a five-point Likert scale ranging from $1=$ strongly disagree to $5=$ strongly agree. Section three contained items related to soldiers' attitudes (i.e., screening can help in early detection of the prostate cancer) and intentions (i.e., I have intentions of screening for PC) toward early detection of PC all on a five-point Likert scale. The questionnaire was piloted and modified with the assistance of a senior researcher.

Consent of respondents was taken before commencing with data collection. Participants were assured of privacy and confidentiality, and the identities of respondents were not taken. Participation was purely voluntary, and no respondent was coerced or lured to participate. The questionnaires were destroyed after entering the data, and information was deleted from the computer and data storage devices after the final report.

Data were analyzed with the aid of Statistical Package for the Social Sciences (SPSS), version 22.0. The questionnaire was coded, and data were entered into the analytical software (SPSS) version 22.0. Data cleaning was done, and inconsistencies for wrong input scores were rectified before carrying out the main analysis. Univariate and bivariate analyses were carried out, and results were presented using frequency tables, bar charts and cross-tabulation.

\section{Results}

It was found that out of the 140 respondents, $72.3 \%$ was married, $72 \%$ had college degree and $69.8 \%$ had attained officer's rank. Exactly $77 \%$ of the respondents earned above GHC 2000 (\$ 400) per month, 91.2\% belonged to the Christian faith and $58.3 \%$ had worked for more than 10 years in the force. It was also found that $59 \%$ of the respondents were young adults (below 40 years) and $66.7 \%$ had subscribed to a health insurance policy.

The results show that $96.3 \%$ of the respondents had heard of prostate cancer and $54.7 \%$ of the respondents cited the media (for example, television, radio and the internet) as their primary source of information. In addition, $76.3 \%$ of the respondents did indicate that they knew at least one PC screening test and $53.3 \%$ of the respondents stated that they were knowledgeable about the signs of prostate cancer. However, $81.3 \%$ of the respondents had never screened or tested for PC. Furthermore, 59.7\% had never received any recommendation from a health worker to undergo PC screening, while $55.8 \%$ of the 
respondents stated that they had not received any health education on prostate cancer. $78.3 \%$ did not know their family history regarding PC. Consequently, the composite score shows that $58.3 \%$ of the respondents were less aware of PC (see Table 1).

In addition, it was found that many of the respondents were less knowledgeable about the signs and risk factors of PC. From Table 2, the average scores ranged between 2.95 and 3.85. This implies that many of the respondents neither disagreed nor agreed with the items on the scale. For instance, many of the respondents either disagreed or were not sure as to whether alcohol consumption (59.1\%), unhealthy diet (63.7\%) and physical inactivity (61.4\%) were risk factors of prostate cancer. Regarding the signs of prostate cancer, many of the respondents either disagreed or were uncertain as to whether persistent headache $(76.7 \%)$, blood in urine or semen (54.5\%), pain in the scrotum (52.6\%) and lower back and thigh pain (60.5\%) were signs of prostate cancer (see Table 2).

Furthermore, it was found that $92 \%$ of the respondents perceived PC screening to be essential for every

Table 1 Prostate cancer awareness among soldiers

\begin{tabular}{lllc}
\hline Characteristics & $\boldsymbol{n}$ & Yes (\%) & No (\%) \\
\hline Have you heard about prostate cancer before? & 136 & 96.3 & 3.7 \\
Received PC information from a health worker? & 134 & 40.3 & 59.7 \\
Are you aware of prostate cancer screening & 139 & 76.3 & 23.7 \\
$\quad$ test? & & & \\
Have you ever screened for prostate cancer? & 139 & 18.7 & 81.3 \\
Do you know anyone with PC & 139 & 31.7 & 68.3 \\
Are you familiar with the signs of PC & 137 & 53.3 & 46.7 \\
Have you ever received health education on & 138 & 44.2 & 55.8 \\
$\quad$ PC? & & & \\
Do you know your family history of PC? & 138 & 21.7 & 78.3 \\
Composite score: less aware=58.3\%, more aware = $41.7 \%$ &
\end{tabular}

male. Exactly, $90.5 \%$ of the respondents perceived that screening for PC can aid in early detection. Only $64.2 \%$ of the respondents perceived that screening can reduce a person's susceptibility to PC. In light of this, many of the respondents perceived PC screening to be important for prevention. Regarding cost of screening, 23.7\% of the respondents perceived screening services to be more expensive. Furthermore, $73.3 \%$ of the respondents perceived that PC screening is less shameful and 57.0\% perceived that $\mathrm{PC}$ screening is less painful. The respondents seemed not to be ignorant of PC screening centres, as $74.1 \%$ of the respondents stated that they knew where to go for PC screening. Generally, $50.8 \%$ of the respondents had good attitude toward early detection but $81.3 \%$ had never screened for PC (see Tables 1 and 3) On a scale of $1-5$, ranging from strongly disagree to strongly agree, respondents were required to indicate the extent to which they disagreed or agreed with the statement 'I have intentions of screening for prostate cancer.' It was found that out of the 132 responses to this item, $11.4 \%$ strongly disagreed, 9.8\% disagreed, while 49.2\% neither agreed nor disagreed. Only, $22.7 \%$ of the respondents agreed and $6.8 \%$ strongly agreed.

Prostate cancer awareness was significantly associated with educational level. Table 4 shows that soldiers who had higher level of education (postgraduate) were more aware of PC than respondents with lower level of educational (secondary). Similarly, respondents with higher rank (officer) were more likely to be aware of prostate cancer compared with respondents with lower (non-commission) rank. The researchers also found that soldiers who had received PC information from health workers were more likely to be aware of PC screening than soldiers who had not received PC information from health workers. The soldiers who were knowledgeable of signs of PC were more likely to be aware of PC.

Table 2 Knowledge about signs and risk factors of prostate cancer

\begin{tabular}{|c|c|c|c|c|c|c|c|c|}
\hline Item & $n$ & Mean & Std. D & $1(\%)$ & $2(\%)$ & $3(\%)$ & $4(\%)$ & $5(\%)$ \\
\hline Excessive alcohol intake can cause PC & 137 & 3.10 & 1.190 & 14.6 & 11.7 & 32.8 & 30.7 & 8.0 \\
\hline Excessive smoking cannot cause PC & 135 & 3.41 & 1.181 & 10.4 & 7.4 & 31.1 & 32.6 & 18.5 \\
\hline Eating too much fatty foods can cause PC & 135 & 3.17 & 1.110 & 9.6 & 12.6 & 41.5 & 23.0 & 12.2 \\
\hline Lack of exercise can cause prostate cancer & 137 & 2.98 & 1.203 & 16.1 & 16.8 & 28.5 & 30.7 & 8.0 \\
\hline Pain in the penis is a sign of $\mathrm{PC}$ & 137 & 3.54 & 1.219 & 10.9 & 7.3 & 19.7 & 40.9 & 21.1 \\
\hline Persistent headache is a sign of PC & 137 & 3.21 & 1.081 & 14.6 & 21.2 & 40.9 & 17.5 & 6.8 \\
\hline Blood in the urine/semen is not a sign & 137 & 3.23 & 1.182 & 13.1 & 8.8 & 32.6 & 37.2 & 10.2 \\
\hline Difficulty/frequent urination is sign of PC & 137 & 3.85 & 1.124 & 8.8 & 0.7 & 16.8 & 44.5 & 29.2 \\
\hline Pain in the scrotum is not a sign of PC & 137 & 3.36 & .954 & 2.2 & 16.8 & 33.6 & 37.2 & 10.2 \\
\hline Pain in the lower back or hip are signs & 137 & 3.18 & 1.016 & 8.0 & 12.4 & 40.1 & 32.2 & 7.3 \\
\hline
\end{tabular}

$1=$ strongly disagree, 2 =disagree, $3=$ neither, $4=$ agree, $5=$ strongly agree 
Table 3 Attitude toward early detection

\begin{tabular}{lllllrrrr}
\hline Item & $\boldsymbol{n}$ & Mean & Std. D & $\mathbf{1 ( \% )}$ & $\mathbf{2 ( \% )}$ & $\mathbf{3 ( \% )}$ & $\mathbf{4 ( \% )}$ & $\mathbf{5 ( \% )}$ \\
\hline PC screening is necessary for every man & 137 & 4.46 & .875 & 2.9 & 1.5 & 3.6 & 30.7 & 61.3 \\
Screening can help in early detection & 137 & 4.49 & .850 & 2.2 & 1.5 & 5.8 & 26.3 & 64.2 \\
Screening reduces a person's chances & 134 & 2.29 & 1.267 & 6.0 & 16.4 & 13.4 & 29.1 & 35.1 \\
Screening is not important for treatment & 135 & 4.41 & 1.010 & 65.2 & 22.2 & 5.2 & 3.7 & 3.7 \\
Screening for PC is expensive or costly & 135 & 2.79 & 1.134 & 15.6 & 21.5 & 39.3 & 15.6 & 8.1 \\
I feel shy or fear to go for PC screening & 135 & 1.93 & 1.154 & 49.6 & 23.7 & 14.1 & 8.9 & 3.7 \\
Screening for PC may be painful & 135 & 2.16 & 1.045 & 36.3 & 20.7 & 34.8 & 6.7 & 1.5 \\
I do not know where to go for screening & 135 & 1.91 & 1.096 & 48.9 & 25.2 & 13.3 & 11.1 & 1.5 \\
Composite score: poor attitude =4.0\%, neutral $=45.2 \%$, good attitude $=50.8 \%$ & & & 11.4 & 9.8 & 49.2 & 22.7 \\
I have intentions of screening for PC & 132 & 3.04 & 1.029 & & 6.8 \\
\hline
\end{tabular}

$1=$ strongly disagree, $2=$ disagree, $3=$ neither, $4=$ agree, $5=$ strongly agree

Table 4 Cross-tabulation of respondents' characteristics and awareness of PC

\begin{tabular}{|c|c|c|c|c|c|}
\hline Patient characteristic & $n$ & Less aware (\%) & More aware (\%) & Chi-square & $p$ value \\
\hline \multicolumn{6}{|l|}{ Educational level } \\
\hline Secondary & 16 & 87.5 & 12.5 & & \\
\hline Diploma & 16 & 81.3 & 18.8 & 13.153 & 0.004 \\
\hline Degree & 62 & 53.2 & 46.8 & & \\
\hline Postgraduate & 33 & 42.4 & 57.6 & & \\
\hline \multicolumn{6}{|l|}{ Rank } \\
\hline Officer & 93 & 50.5 & 49.5 & 8.536 & 0.003 \\
\hline Non-commission & 34 & 79.4 & 20.6 & & \\
\hline \multicolumn{6}{|l|}{ Received PC information } \\
\hline No & 76 & 77.6 & 22.4 & 29.183 & $<0.001$ \\
\hline Yes & 51 & 29.4 & 70.6 & & \\
\hline \multicolumn{6}{|l|}{ Know the signs of PC } \\
\hline No & 56 & 92.9 & 7.1 & 49.286 & $<0.001$ \\
\hline Yes & 71 & 30.0 & 69.0 & & \\
\hline
\end{tabular}

\section{Discussion}

In this study, awareness of prostate cancer among soldiers was found to be below expectation. This is consistent with findings of prior studies in some African countries [1-3]. Among the soldiers who had heard of PC, the media (radio, television, internet etc.) was their primary source of information. This suggests that the mass media can be an effective tool for increasing PC awareness among soldiers in Ghana.

Even though many of the soldiers indicated that they were familiar with the signs of prostate cancer, they could not demonstrate adequate knowledge of the disease. Previous studies have confirmed that there is low knowledge of PC among high-risk population such as Africans [10, 12-15]. This implies that the mere fact of hearing about $\mathrm{PC}$ is not enough to make someone knowledgeable about the disease. Reasons underlying this finding may include low public education on PC. For example, many of the soldiers stated that they had never received any education on $\mathrm{PC}$ or a recommendation from a health worker to get tested. In Ghana, there is low political will or interest for non-communicable diseases which result in low funding for health promotion activities $[16,17]$. This may explain why many of the soldiers could not demonstrate good knowledge about the signs and risk factors of PC. Health promotion activities in Ghana are skewed toward communicable disease like AIDS and malaria, with little attention on non-communicable disease like cancer [16]. It is therefore necessary for management of the GAF to invest more resources into health promotion activities emphasizing on risk factors and signs of PC.

It was also found that the soldiers perceived screening to be beneficial coupled with less perceived barriers to the uptake of screening services. However, many of the soldiers had never tested for PC. In addition, the soldiers demonstrated weak intentions of getting screened. This has been confirmed by previous studies. For instance, studies have found low interest in early detection of 
prostate cancer among population as risk such as Africa men $[18,19]$. This finding is not surprising, since many of the soldiers perceived that PC is of less severity and could be cured. Also, the soldiers perceived that PC is for older people (60 years and above). Most of the respondents in this study were below 40 years and therefore might have perceived themselves not to be at risk of PC. Additionally, people are more likely to adopt preventive health behaviors if it is recommended by a health professional. However, many of the soldiers in this study did indicate that they had never been informed by a health worker to get tested.

Furthermore, it was found that awareness of PC was significantly associated with educational level, rank, having received information about PC and knowledgeable about the signs of PC. These findings have been confirmed by previous studies $[2,3,13]$. These findings suggest that an improvement in educational status and health education activities can promote the prevention or early detection of PC. Going forward, the management of GAF can liaise with the Ministry of Health to organize health education activities on PC for soldiers in Ghana emphasizing on risk factors, the complexity and financial burden associated with late detection and demystifying the side effects of PC therapies. Additionally, the management of GAF may liaise with the Ministry of Health to organizing prostate cancer screening activities for soldiers in Ghana. This can aid in prevention, early detection and effective management of prostate cancer among these essential service providers.

This study provides valuable information for health interventions in Ghana, especially among soldiers. However, generalization of the findings must be done with caution since the study was limited to only soldiers in Burma Camp. Hence, future studies may consider including soldiers from other camps.

\section{Conclusion}

In conclusion, soldiers in this study were less aware of prostate cancer and had limited knowledge regarding risk factors and signs of the disease. The soldiers had positive attitude toward early detections of prostate cancer but low intentions of getting tested.

\section{Supplementary information}

Supplementary information accompanies this paper at https://doi. org/10.1186/s12301-019-0004-3.

Additional file 1. STROBE Statement-checklist of items that should be included in reports of observational studies.

\section{Abbreviations}

PC: Prostate cancer; GAF: Ghana Armed Forces; SPSS: Statistical Package for the Social Sciences; AIDS: Acquired immunodeficiency syndrome.

\section{Acknowledgements}

The researchers would like to thank the management of the Ghana Armed Force for granting permission for this study to be conducted.

\section{Authors' contributions}

JGN (adjoanecku@gmail.com) conceived and designed the study and collected the data. JGN conducted the analysis with inputs from EAA (emmaanaba24@gmail.com). EAA drafted the initial manuscript. AAA (aabuosi@ug.edu.gh) critically revised drafts. All authors read and approved the final manuscript.

\section{Funding}

This study received no external funding.

\section{Availability of data and materials}

The datasets used and/or analyzed during the current study available from the corresponding author on reasonable request.

\section{Ethics approval and consent to participate}

Our manuscript is an excerpt from the first author's dissertation. During the time of the study, the college was considerate of students seeking external IRB approval. However, this study had the approval of the college's committee, which is however not a standard or formal IRB committee. Hence, do not give reference numbers. In addition, our manuscript is not a new submission; it has already been accepted for publication in your reputable journals [Manuscript \#AFJU-D-18-00172 (R1)]. Moreover, no implicit or explicit damage was made to participants. This study did not involve patients. Our participants were more comfortable with providing written consent after signing the declarations on the consent form. Participation was voluntary and respondents had the feel will to opt out at any stage of the data collection. Biological samples were not taken from respondents.

\section{Consent for publication}

Not applicable.

\section{Competing interests}

The authors declare that they have no competing interests.

\section{Author details}

${ }^{1} 37$ Military Hospital, Accra, Ghana. ${ }^{2}$ Public Administration and Health Services Management, University of Ghana Business School, Accra, Ghana.

Received: 22 October 2019 Accepted: 29 October 2019

Published online: 10 December 2019

\section{References}

1. Jandorf L, Chang MS, Smith K, Florio A, Hall SJ (2007) Community-based free prostate cancer screening program. Prog Community Health Partnersh Res Edu Action 1(3):215

2. Punga-Maole A, Moningo D, Kayembe P, Tshikuela M, Kabongo J (2008) Study of prostate cancer screening in a population of employees of a Kinshasa company in the Democratic Republic of Congo. Detection rate and nutritional and geographical risk factors. Progres en urologie: journal de l'Association francaise d'urologie et de la Societe francaise d'urologie 18(8):512-518

3. Oladimeji O, Bidemi YO, Olufisayo J-AY, Sola AO (2010) Prostate cancer awareness, knowledge, and screening practices among older men in Oyo State, Nigeria. Int Q Community Health Edu 30(3):271-286

4. World Health Ranking. https://www.worldlifeexpectancy.com/world -health-rankings

5. Abayie H (2009) Prostate Awareness Foundation, press release on prostate cancer. https://www.modernghana.com/sports/157550/1/prost ate-foundation-hails-government.html

6. Arthur F, Yeboah F, Adu-Frimpong M, Sedudzi E, Boateng K (2006) Prostate cancer screening in Ghana-a clinical benefit? J Sci Technol (Ghana) 26(1):1-7

7. Obu R (2014) Investigating the impact of a healthy relationship on Ghanaian men diagnosed with prostate cancer and cultural issues in 
Ghana-a discussion paper on the physical and psychosocial effects of the disease and its treatment. Glob J Environ Sci Technol 1(1):001-007

8. Wiredu EK, Armah HB (2006) Cancer mortality patterns in Ghana: a 10-year review of autopsies and hospital mortality. BMC Public Health 6(1):159

9. Binka C, Nyarko SH, Doku DT, Antwi K (2014) Prostate cancer knowledge, perceptions and screening behaviour among male University students in Ghana. Int J Sci Basic Appl Res (IJSBAR) 17(1):362-371

10. Otoo V (2010) Awareness of Prostate Cancer among male soldiers in the Ghana Armed Forces. University of Ghana, Accra

11. Joseph HJ (2006) Determinants of prostate cancer screening in a sample of African American military servicemen. Mil Med 171(5):430-435

12. Magoha G (2000) Management and survival in advances prostate cancer in Nairobi. East African medical journal 77(5):260-263

13. Kabore FA, Zango B, Sanou A, Yameogo C, Kirakoya B (2011) Prostate cancer outcome in Burkina Faso. Infect Agent Cancer 6(Suppl 2):S6

14. Weinrich SP, Seger R, Miller BL, Davis C, Kim S, Wheeler C, Weinrich M (2004) Knowledge of the limitations associated with prostate cancer screening among low-income men. Cancer Nurs 27(6):442-451

15. Atulomah NO, Olanrewaju MF, Amosu AM, Adedeji O (2010) Level of awareness, perception and screening behavior regarding prostate cancer among men in a rural community of Ikenne Local Government Area, Nigeria. Prim Prev Insights 2010(2):11-20

16. Bosu W (2013) Accelerating the control and prevention of non-communicable diseases in Ghana: The Key Issues. Postgrad Med J Ghana 2(1):32-33

17. Ministry-of-Health (2012) Strategy for the management prevention and control of chronic non-communicable diseases in Ghana 2012-2016. Ministy of Health (Ghana), Accra

18. Yeboah-Asiamah B, Yirenya-Tawiah D, Baafi D, Ackumey M (2017) Perceptions and knowledge about prostate cancer and attitudes towards prostate cancer screening among male teachers in the Sunyani Municipality, Ghana. Afr J Urol 23(4):184-191

19. Nakwafila O, Nyarko K, Quaye I, Angula P (2017) Investigation on knowledge, attitude and practices of Namibian men regarding prostate cancer among men attending Intermediate Hospital Oshakati, Namibia, 2016. Pan Afr Med J 3(81):102-111

\section{Publisher's Note}

Springer Nature remains neutral with regard to jurisdictional claims in published maps and institutional affiliations.

\section{Submit your manuscript to a SpringerOpen ${ }^{\circ}$ journal and benefit from:}

- Convenient online submission

- Rigorous peer review

- Open access: articles freely available online

- High visibility within the field

- Retaining the copyright to your article

Submit your next manuscript at $\boldsymbol{\nabla}$ springeropen.com 